\title{
The Cost of Diabetes Care Programs for Type 2 Diabetes in Argentina: A Probabilistic Sensitivity Analysis
}

\section{Joaquín E Caporale, Jorge F Elgart and Juan J Gagliardino*}

Health Economics and Quality of Care Board of the Argentine Diabetes Society, CENEXA - Centro de Endocrinología Experimental y Aplicada (UNLP-CONICET LA PLATA, Centro Colaborador OPS/OMS para Diabetes), Facultad de Ciencias Médicas UNLP, La Plata, Argentina

\begin{abstract}
Introduction: Structured diabetes care programs in Argentina are scarce and do not inform about their cost using micro costing techniques.
\end{abstract}

Aim: To estimate the incremental costs of a health care program for type 2 diabetes without complications implemented at sub-national level in Argentina during 2005.

Methods: United Kingdom Prospective Diabetes Study and Latin American Diabetes Association guidelines were used to identify which resources should be part of a diabetes program to implement in two Argentinean provinces Córdoba and Misiones - with high and low socioeconomic characteristics, respectively. A micro costing approach was used to estimate costs from the perspective of a public health payer, taking a province without diabetes program as a comparative scenario. Probabilistic sensitivity analysis following Monte Carlo simulation was used to determine the number of visits and practices, probability of insulin treatment, combination therapy for hypertension, annual number of test strips and unit cost of all resources used.

Results: The main component of the annual incremental cost per patient in both provinces was self-monitoring blood glucose $(\sim 50 \%)$, followed by treatment of diabetes, dyslipidemia and hypertension. The lowest cost corresponded to human resources ( $<5 \%)$. The annual incremental cost per patient was $32 \%$ higher in Córdoba due to the pharmacological treatment of diabetes $(>90 \%)$.

Discussion: This study provides original evidence for Argentina that could facilitate the development and further evaluation of diabetes programs and resource use optimization in the public health care subsector in other provinces/ countries with comparable socioeconomic and health care settings.

Keywords: Cost of care; Type 2 diabetes; Probabilistic sensitivity analysis; Provincial diabetes program; Diabetes economics; Treatment costs

\section{What Gap This Fills}

\section{What we already know}

International reports show that an important economic investment is required for the implementation of diabetes care programs. However, data on such cost are not available in Argentina.

\section{What this study adds}

This first evaluation of the cost of implementing an ideal diabetes care program in Argentina at subnational level shows a marked heterogeneity in the relative economic weight of the different program components and also among provinces, being self-monitoring blood glucose the main determinant of the total cost. It is thus reasonable to implement precise guidelines together with a program, for its rational use according to the type of treatment and $\mathrm{HbA}_{1 \mathrm{c}}$ target goals.

\section{Introduction}

The continuously increasing prevalence of diabetes worldwide and of the associated invalidating complications in people with poor disease control represent a serious problem for health care systems and for society $[1,2]$. This situation can be alleviated through the implementation of structured health care programs for diabetes and its associated cardiovascular risk factors, that facilitate patient access to appropriate care and treatment. ${ }^{3}$ However, the effective implementation of such programs at public health care level requires sufficient scientific knowledge an data on their economic costs.

In Argentina, diabetes prevalence in the adult population increased from $8.4 \%$ in 2005 to $9.6 \%$ in 2009 [4]. Moreover, most people with diabetes have poor control of hyperglycemia and the associated cardiovascular risk factors [5] and present chronic complications [6] these facts negatively impact upon costs of care [7] and productivity [8].

Argentina has a federal organization with 24 subnational governments, in which the health care system comprises three subsystems: 1) the public health care system, 2) the social security system, and 3) the pre-paid health care subsector. To cope with the care demand, almost all the Argentinean provinces have implemented diabetes programs with different degree of treatment provision/ coverage. Their general objectives are in line with those formulated at national level: prevention, promotion, training, health care coverage, and provision of drugs and supplies for control and treatment.

Data on the economic cost of these programs are unavailable or difficult to obtain, mainly due to non-existent, incomplete or deficient registries. This fact represents a serious constraint to achieving

*Corresponding author: Juan J. Gagliardino, CENEXA (UNLP-CONICET LA PLATA), Facultad de Ciencias Médicas, UNLP Calles 60 y 120, 1900 La Plata, Argentina, E-mail: cenexa@speedy.com.ar

Received November 15, 2011; Accepted December 26, 2011; Published December 28, 2011

Citation: Caporale JE, Elgart JF, Gagliardino JJ (2011) The Cost of Diabetes Care Programs for Type 2 Diabetes in Argentina: A Probabilistic Sensitivity Analysis. Primary Health Care: Open Access 1:105. doi:10.4172/2167-1079.1000105

Copyright: (C) 2011 Caporale JE, et al. This is an open-access article distributed under the terms of the Creative Commons Attribution License, which permits unrestricted use, distribution, and reproduction in any medium, provided the original author and source are credited. 
program sustainability and resource use optimization/allocation, and to developing new effective diabetes programs. To overcome this situation, we estimated the incremental health care costs of two ideal provincial programs for the treatment of people with type 2 diabetes (T2DM) without complications for the year 2005.

Córdoba and Misiones were selected as representative provinces from two Argentinean Regions: Pampean and Northeast, respectively. Selection criteria based on the following: 1) the Pampean and Northeast Regions have the lowest and highest percentage of people with unsatisfied basic needs, respectively; 2) the Northeast Region has the lowest activity and employment rates, whereas the Pampean Region has the highest [9] and 3) the percentage of people covered only by the public health care system is $35 \%$ and $49 \%$ for Córdoba and Misiones, respectively (First National Risk Factor Survey). Additionally, inclusion of provinces with such uneven socioeconomic profiles would allow the potential application of the conclusions obtained to other provinces or countries with comparable socioeconomic and health care settings, enabling them to estimate the health care costs of a program based on diabetes prevention, treatment and control, as proposed by international good practice guidelines.

\section{Methods}

Resource identification for total and incremental cost estimation $[10,11]$ based on the Latin American Diabetes Association Guidelines for the Management of T2Dm, [12] the UKPDS resource utilization, [13] and the technical report of the CDC Diabetes Cost-effectiveness Group [14]. Incremental cost analysis was performed using a null scenario without diabetes program.

Three groups of resources were used for cost analysis: human resources, practices and drugs. Unit costs for drugs, practices, supplies and administrative salaries (human resources) were provided by the provinces of Córdoba and Misiones.

Physician cost resulted from the combination of mean duration of a consultation, annual number of consultations, and fee per hour.

Administrative costs resulted from work hours (45 h/week) and salary per hour in both provinces. Cost per patient in both provinces was calculated considering the total number of people with diabetes covered by the Córdoba Diabetes Program in 2005 (Misiones had no Diabetes Program at that time), equivalent to $18 \%$ of the provincial population without medical coverage [15].

The cost of practices and tests was estimated multiplying the proposed number per year by the unit cost informed by each province (Table 1). Figures were equal to those used in the UKPDS [13] and the ALAD guidelines, [12] validated and adjusted after expert opinion consultation. Unit costs were those of the public sector for 2005 in Córdoba and 2009 in Misiones; prices were not deflated assuming a fixed-price by contract. The unit costs for micro albuminuria and stress test were obtained from the provincial social securities of both provinces.

Drug costs were calculated considering daily doses, annual consumption, probability of use and unit cost from provincial and social security drug purchases for 2005. The cost of therapy for diabetes and hypertension (monotherapy and combined therapy) was weighed to obtain an expected cost for a specific pharmacological treatment, namely, diabetes, hypertension/ dyslipemia, and self-monitoring blood glucose (SMBG). The probability of use of each pharmacological treatment was applied to weigh several treatment options; probabilities were obtained from the Argentinean Qualidiab registry [6] provincial records (personal communications) and expert opinion according to daily care and good practice guidelines.

Diabetes treatment cost was also estimated as a probability-weighted average of use of monotherapy with oral agents (glibenclamide or metformin), monotherapy with insulin (human, regular or NPH), and combined therapy with oral agents. The same methodology was applied for hypertension, but with a larger number of drugs (atenolol, enalapril, amlodipine and hydrochlorothiazide), thus allowing to average two alternative combination therapies with 2 or 3 drugs. The treatment proposed for dyslipemia was based only in the use of atorvastatin.

Costs for SMBG were estimated considering a weighted product between the proposed number of test strips (treated or not with insulin) and the corresponding unit cost. The proposed number of test strips was similar to the one used in the UKPDS and validated by the authors with local patterns of consumption. The cost of lancets was calculated with values from Córdoba for both provinces.

We performed a probabilistic sensitivity analysis using Monte Carlo technique with 10,000 iterations. The variables included in the analysis were number of annual visits, salary per hour, number of annual practices, unit cost of each practice, unit cost of each drug, probability of insulin use and of combined therapy with two drugs for hypertension; mean weight (a diabetic population with higher weight will need a larger number of insulin units/day; this information was necessary to determine the number of insulin units as a function of the dose proposed [0.6 IU/kg/day]); number of annual strips (SMBG is more frequent in people treated with insulin, therefore, annual strip consumption is higher); unit cost of supplies for SMBG (lancets and strips).

The probability of insulin use was considered a pivotal input under a beta distribution; this input was related to the chances of having other treatments, such as oral antidiabetic drugs (monotherapy $v s$. combined therapy). For the probability of being treated for hypertension with two drugs, the same assumption was used, i.e., a pivotal input under a beta distribution to reflect the relationship with the chances of being treated differently.

\section{Results}

The incremental annual health care cost per patient (deterministic terms) was AR\$ 1,503 and AR\$ 1,141 for Córdoba and Misiones, respectively. The absolute difference between provinces (stochastic terms) adjusted to a normal distribution (AR\$ $344 \pm 135$ ) was slightly lower than that recorded with the deterministic model.

Table 1 shows the annual frequency of practices and tests and table 2 show the cost of the proposed ambulatory treatment in each province, as recommended by the ALAD and other international guidelines to control hyperglycemia and the associated cardiovascular risk factors in people with T2DM.

Table 2 shows the annual health care costs per patient of the two provincial programs. In both provinces, SMBG was the main component of this cost (about $50 \%$ of the total), followed by the pharmacological treatment of diabetes, dyslipidemia and hypertension. Conversely, human resources only represented $<5 \%$ of the expected annual incremental cost per patient.

The total cost of the program in Córdoba was 32\% higher than in Misiones; such difference was not homogeneously distributed among 
Citation: Caporale JE, Elgart JF, Gagliardino JJ (2011) The Cost of Diabetes Care Programs for Type 2 Diabetes in Argentina: A Probabilistic Sensitivity Analysis. Primary Health Care: Open Access 1:105. doi:10.4172/2167-1079.1000105

Page 3 of 5

its different components; in general, differences were higher for Córdoba, excepting practices, whose costs were higher in Misiones. Since physical units (quantities and rates) were the same for both provinces, the mentioned differences might be ascribed to an uneven cost per unit. In fact, the unit cost of glibenclamide, metformin and insulin was $179 \%, 64 \%$ and $146 \%$ higher in Córdoba than in Misiones. Similar differences were reported for the pharmacological treatment of associated cardiovascular risk factors. In the case of diabetes SMBG, the unit cost of strips ( $48 \%$ higher in Córdoba) was the only source of variation. Regarding the unit cost of human resources, each province determined the gross monthly salary throughout the annual budget.

Finally, although differences in the aggregate cost of practices and studies were not quantitatively important, they were relevant for microalbuminuria (582\% higher in Misiones) and lipid profile (50\% higher in Córdoba). In the case of microalbuminuria, the difference could be due to the fact that the only available information in Misiones came from the provincial social security, where costs are commonly higher than in the public health subsector.

The best statistical distributions of annual incremental health care costs per patient in both provincial programs were identified with the probabilistic sensitivity analysis, with a log-normal distribution for Córdoba and a gamma distribution for Misiones. Results by province were as follows: a) mean incremental costs were $32 \%$ lower in Misiones than in Córdoba; b) only $10 \%$ of simulated cases were similar in both provinces, and c) dispersion from the mean adjusted value was higher in Córdoba (Figure 1).

Table 3 shows the main determinants of variability in incremental annual health care costs per patient. Such variability can be explained by a) the probability to use insulin or not, b) the required number of strips and their unit cost, and c) the number of $\mathrm{HbA}_{1 \mathrm{c}}$ assessments. The impact of each variable was different in each province.

One of the main aspects of our analysis is that SMBG was the principal determinant of treatment costs. Therefore, its use should be regulated to avoid financial uncoupling and inequities when implementing insulin treatment in T2DM, which would demand more frequent monitoring.

\begin{tabular}{|l|l|l|l|}
\hline Practice/Test & Number & Unit cost & \\
\cline { 4 - 4 } & & Cordoba & Misiones \\
\hline HbA $_{1 \mathrm{c}}$ & 4 & $\$ 15.0$ & $\$ 20.0$ \\
\hline Microalbuminuria & 1 & $\$ 2.2$ & $\$ 15.0$ \\
\hline ECG & 1 & $\$ 15.0$ & $\$ 20.0$ \\
\hline Stress test & 1 & $\$ 10.8$ & $\$ 10.8$ \\
\hline Lipid profile & $1(4)$ & $\$ 10.1$ & $\$ 5.0$ \\
\hline Eye exam & 4 & $\$ 10.1$ & $\$ 5.0$ \\
\hline Urine test & 1 & $\$ 1.8$ & $\$ 1.0$ \\
\hline Albuminuria & 1 & - & $\$ 1.0$ \\
\hline Creatinine & 1 & $\$ 1.5$ & $\$ 1.0$ \\
\hline Blood test + ERS & 1 & $\$ 13.5$ & $\$ 8.0$ \\
\hline Glycemia & 4 & $\$ 0.92$ & $\$ 1.0$ \\
\hline
\end{tabular}

*With dyslipidemia, 4 lipid profiles should be performed

ECG, electrocardiogram; ERS, erythrocyte sedimentation rate

Table 1: Annual frequency of practices and tests in the proposed ambulatory treatment.

\begin{tabular}{|c|c|c|c|}
\hline & $\begin{array}{l}\text { Córdoba } \\
\$(\%)\end{array}$ & $\begin{array}{l}\text { Misiones } \\
\$(\%)\end{array}$ & $\begin{array}{l}\text { Difference } \\
(\%)\end{array}$ \\
\hline Human Resources & $58.57(4)$ & $42.74(3.7)$ & +37 \\
\hline Physicians $(\$ / h)$ & 52.40 & 37.70 & \\
\hline Administrative staff $(\$ / h)$ & 6.17 & 5.04 & \\
\hline Diabetes pharmacological treatment & $259.32(17)$ & $135.78(12)$ & +91 \\
\hline Monotherapy (OHA, 54\%) & 77.01 & 39.44 & \\
\hline Monotherapy (Insulin, 30\%) & 643.64 & 339.54 & \\
\hline $\begin{array}{l}\text { Combination therapy (2 OHA, } \\
16 \%)\end{array}$ & 154.03 & 78.88 & \\
\hline SMBG & $732.26(49)$ & $550.59(48)$ & +33 \\
\hline T2DM with insulin (30\%) & 1344.82 & 1004.19 & \\
\hline T2DM without insulin $(70 \%)$ & 469.73 & 356.19 & \\
\hline $\begin{array}{l}\text { Hypertension/dyslipemia } \\
\text { pharmacological treatment }\end{array}$ & $293.97(20)$ & $245.64(22)$ & +20 \\
\hline Hypertension & 60.37 & 55.84 & \\
\hline Monotherapy (40\%) & 32.89 & 30.84 & \\
\hline $\begin{array}{l}\text { Combined therapy ( } 2 \text { drugs) } \\
(40 \%)\end{array}$ & 65.14 & 61.55 & \\
\hline $\begin{array}{l}\text { Combined therapy ( } 3 \text { drugs) } \\
(20 \%)\end{array}$ & 105.78 & 94.40 & \\
\hline Dyslipemia & 233.60 & 189.80 & \\
\hline Practices and tests & $158.74(11)$ & $165.85(15)$ & -42 \\
\hline $\begin{array}{l}\text { Expected annual and individual } \\
\text { incremental cost }\end{array}$ & 1502.86 & 1140.59 & +32 \\
\hline
\end{tabular}

OHA, oral hypoglycemic agent; SMBG, self-monitoring blood glucose; T2DM, type 2 diabetes mellitus

Table 2: Expected annual incremental cost per patient according to the proposed treatment. Deterministic scenario.

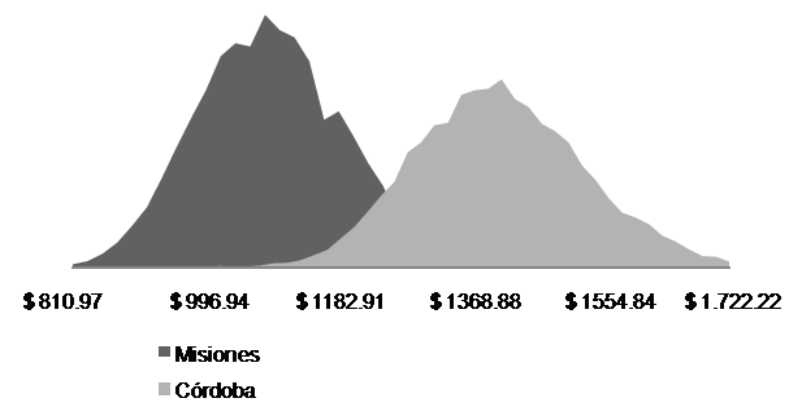

Figure 1: Expected annual and individual incremental costs of the proposed treatment in Córdoba and Misiones (Monte Carlo simulation probability density function).

\section{Discussion}

The current report provides the first cost evaluation of implementing an ideal provincial diabetes care program. Since this evaluation was performed in two provinces with highly different overall and health care budgets, the data could be translated to other provinces/countries with comparable socioeconomic and health care settings.

The estimated incremental cost per person represent about $10 \%$ of per capita gross domestic product of Argentina and it was approximately 7 times higher than the public health expenditure per capita in both provinces. Considering the target population in each province, the additional cost represents $19 \%$ and $11 \%$ of the provincial health expenditure of Córdoba and Misiones, respectively. 
The estimated incremental cost per person represent about $10 \%$ of per capita gross domestic product of Argentina and it was approximately 7 times higher than the public health expenditure per capita in both provinces. Considering the target population in each province, the additional cost represents $19 \%$ and $11 \%$ of the provincial health expenditure in the provinces of Córdoba and Misiones, respectively [16].

A marked heterogeneity was recorded in the relative weight of the different program components, being that of drugs and medical supplies the highest (86\%). Within this figure, of the risk factors associated to T2DM (hyperglycemia, hypertension and dyslipidemia), hyperglycaemic treatment (conditioned by SMBG cost) had the highest magnitude and hypertension the lowest. These data coincide with those reported in the CDC study, i.e., hyperglycemia and hyperlipidemia treatment was cost-effective while hypertension treatment was costsaving [14]. This might be an important element to consider when establishing priorities in case of insufficient budget availability.

The scarce relative weight of medical care costs (human resources) on total program costs merits an additional analysis. Since the quality of care provided partly depends on the time devoted to patients, our results suggest that the allocation of human resources to a diabetes care program might be a key condition to improve its outcomes without seriously affecting its cost.

The different program cost in both provinces (32\%) was also remarkable. The methodology used in the study allows the identification of the item/s involved but not the cause/s of such a difference. Another study design would be needed to answer this question.

The probabilistic sensitivity analysis confirmed the information presented in Table 2, i.e., that SMBG was the main determinant of such cost. Since SMBG is a useful tool for the education, control and treatment of people with T2DM, it would be necessary to optimize its use rather than to discontinue it, as recommended by the International Diabetes Federation [1,2]. Consequently, it would be reasonable to establish precise guidelines for strip provision according to type of treatment, $\mathrm{HbA}_{1 \mathrm{c}}$ target goals and equity criteria, rather than granting them based on the free demand of the couple provider/user.

The sensitivity analysis also states the relative importance of the number of $\mathrm{HbA}_{1 \mathrm{c}}$ performed over the total cost per person. We considered a mean number of $4 \mathrm{HbA}_{1 \mathrm{c}}$ tests per year under a Poisson distribution, but even in developed countries such as the United States such number is much lower. Thus, in this ideal world the total program cost per person would be overestimated.

Several factors limit our conclusions, namely: a) a null scenario (a hypothetical province without diabetes care program was used to analyze and compare costs per province); thus results are not conclusive, b) the lack of equivalent units of measure in both provinces, which limited the effective comparison of costs, and c) the unavailability of a systematic record of clinical and metabolic indicators and of drug and device utilization. These limitations should promote the development and implementation of data record strategies to correct such shortcoming. Anyhow, our results are the only comparative economic data published and available in Argentina. Therefore, they provide a preliminary objective diagnosis of the cost of a diabetes care program from the perspective of a public health payer. An additional value derives from the fact that data were obtained from two provinces with completely different socioeconomic scenarios; thus, the applicability of outcomes to health care systems with quite uneven availability of economic resources is higher.

Altogether, our results represent a warning for healthcare providers and financing entities to consider the total cost and the different components when planning the implementation of diabetes

\begin{tabular}{|c|c|c|c|c|}
\hline & \multicolumn{2}{|c|}{ Contribution to variance } & \multicolumn{2}{|c|}{ Correlation coefficient } \\
\hline & Córdoba & Misiones & Córdoba & Misiones \\
\hline Unit cost of strips (1 strip) & 0.1806 & 0.2818 & 0.4085 & 0.5126 \\
\hline Probability to use insulin in T2DM & 0.4752 & 0.2743 & 0.6626 & 0.5058 \\
\hline Number of $\mathrm{HbA}_{1 \mathrm{c}}$ practices/year & 0.0636 & 0.1847 & 0.2425 & 0.4150 \\
\hline Number of strips and lancets/year in T2DM without insulin & 0.0789 & 0.0609 & 0.2700 & 0.2384 \\
\hline Number of strips and lancets/year in T2DM with insulin & 0.0672 & 0.0491 & 0.2493 & 0.2140 \\
\hline Number of ECG/year & 0.0133 & 0.0403 & 0.1108 & 0.1938 \\
\hline Number of microalbuminuria/year & 0.0002 & 0.0275 & 0.0137 & 0.1602 \\
\hline Unit cost of lancets (1 lancet) & 0.0092 & 0.0173 & 0.0924 & 0.1269 \\
\hline Unit cost of atorvastatin (1 mg) & 0.0116 & 0.0134 & 0.1037 & 0.1120 \\
\hline Number of stress tests/year & 0.0063 & 0.0121 & 0.0760 & 0.1064 \\
\hline Number of lipid profiles/year in people with dyslipemia & 0.0281 & 0.0087 & 0.1612 & 0.0900 \\
\hline Weight $(\mathrm{Kg})[0.6 \mathrm{IU} / \mathrm{Kg} / \mathrm{day}]^{*}$ & 0.0314 & 0.0061 & 0.1703 & 0.0753 \\
\hline Number of consultations to physician/year & 0.0049 & 0.0041 & 0.0673 & 0.0619 \\
\hline Unit cost of $\mathrm{HbA}_{1 \mathrm{c}}$ (1 practice) & 0.0003 & 0.0027 & 0.0168 & 0.0501 \\
\hline Number of additional consultations to physician/year & 0.0025 & 0.0020 & 0.0476 & 0.0434 \\
\hline
\end{tabular}

*The insulin dose proposed was $0.6 \mathrm{IU} / \mathrm{kg}$ body weight

T2DM, type 2 diabetes mellitus; ECG, electrocardiogram

Table 3: Probabilistic sensitivity analysis of the expected annual and individual incremental treatment costs in both provinces. 
Citation: Caporale JE, Elgart JF, Gagliardino JJ (2011) The Cost of Diabetes Care Programs for Type 2 Diabetes in Argentina: A Probabilistic Sensitivity Analysis. Primary Health Care: Open Access 1:105. doi:10.4172/2167-1079.1000105

Page 5 of 5

care programs; also, the need for the early establishment of appropriate guidelines to extend care coverage and avoid economic imbalance and distributive inequities.

\section{Acknowledgements}

The authors, on behalf of the Health Economics and Quality of Care Board of the Argentine Diabetes Society, are grateful to MI de Pianesi and C Dutescu (Misiones Diabetes Program); J Waitman and C García (Córdoba Diabetes Program), and the following persons and institutions: R López Santi (Ministry of Health, Province of Buenos Aires; AB García Albarracín (Secretary of Health of the city of Buenos Aires); A Llopis (Ministry of Health, Province of Catamarca); C Szymula (Ministry of Health, Province of Chaco); G Gricman (Ministry of Health, Province of Chubut); S Garbe and J Catán (Ministry of Health, Province of Entre Ríos); M Ratti (Ministry of Health, Province of Formosa); P Corro (Ministry of Health, Province of Jujuy); J Olivares, C de María and M Valentini (Ministry of Health, Province of La Pampa); R Quevedo (Ministry of Health, Province of La Rioja); ME Charparín (Ministry of Health, Province of Mendoza); C Talazzi (Ministry of Health, Province of Salta); C Busso and S Grasso (Ministry of Health, Province of Santa Fé); OM Abdala (Ministry of Health, Province of Santiago del Estero); R Maza and L Otiñano (Ministry of Health, Province of San Juan); SA Sosa (Ministry of Health, Province of San Luis); R Gandarillas (Ministry of Health, Province of Tierra del Fuego); L Baza and C Du Plessis (Ministry of Health, Province of Tucumán). Thanks are also due to A Di Maggio for careful manuscript preparation.

\section{Funding}

This study was partially supported with funds provided by the Argentine National Research Council.

\section{Competing Interests}

None declared.

\section{References}

1. International Diabetes Federation (2009) Self-monitoring of blood glucose in non-insulin-treated type 2 diabetes. Recommendations based on a Workshop of the International Diabetes Federation Clinical Guidelines Taskforce in collaboration with the SMBG International Working Group, Brussels.

2. International Diabetes Federation (2009) IDF Diabetes Atlas. Fourth Edition, Brussels.

3. Gagliardino JJ, Olivera E, Etchegoyen GS, Guidi ML, Caporale JE, et al. (2006) PROPAT: A study to improve the quality and reduce the cost of diabetes care. Diabetes Res Clin Pract 72: 284-291.

4. Ferrante D, Linetzky B, Konfino J, King A, Virgolini M, et al. (2011) Encuesta
Nacional de Factores de Riesgo 2009: evolución de la epidemia de enfermedades crónicas no transmisibles en Argentina. Estudio de corte transversal Rev Argent Salud Pública 2: 34-41.

5. Chan JC, Gagliardino JJ, Baik SH, Chantelot JM, Ferreira SR, et al. (2009) IDMPS Investigators. Multifaceted determinants for achieving glycemic control: the International Diabetes Management Practice Study (IDMPS). Diabetes Care 32: 227-233

6. Gagliardino JJ, de la Hera M, Siri F, Grupo de Investigación de la Red QUALIDIAB (2001) Evaluación de la calidad de la asistencia al paciente diabético en América Latina. Rev Panam Salud Pública 10: 309-337.

7. Williams R, Van Gaal L, Lucioni C, CODE-2 Advisory Board (2002) Assessing the impact of complications on the costs of Type II diabetes. Diabetologia 45: S13-S17.

8. Olivera E, Pérez Duhalde E, Gagliardino JJ (1991) Costs of temporary and permanent disability induced by diabetes. Diabetes Care 14: 593-596.

9. Instituto Nacional de Estadísticas y Censos. Encuesta Permanente de Hogares (2005) Informe de Prensa: Mercado de trabajo: principales indicadores, Resultados del $1^{\circ}$ trimestre de, Buenos Aires: INDEC.

10. Drummond MF, O'Brien B, Stoddart GL, Torrance GW (1997) Methods for the Economic Evaluation of Health Care Programmes (2nd edn), Oxford University Press, New York.

11. Gold MR, Siegel JE, Russell LB, Weinstein MC (1996) Cost-effectiveness Analysis in Health and Medicine, Oxford University Press, New York.

12. Asociación Latinoamericana de Diabetes (2000) Guías ALAD 2000 para el diagnóstico y manejo de la diabetes mellitus tipo 2 con medicina basada en evidencia. Rev Asoc Latinoam Diabetes.

13. UK Prospective Diabetes Study (UKPDS) Group (1998) Intensive bloodglucose control with sulphonylureas or insulin compared with conventional treatment and risk of complications in patients with type 2 diabetes (UKPDS 33). Lancet 352: 837853.

14. CDC Diabetes Cost-effectiveness Group (2002) Cost-effectiveness of intensive glycemic control, intensified hypertension control, and serum cholesterol level reduction for type 2 diabetes. JAMA 287: 2542-2551.

15. Ministerio de Salud de la Nación: Primera Encuesta Nacional de Factores de Riesgo (2006) Primera Edición, Buenos Aires.

16. Dirección de Análisis de Gasto Público y Programas Sociales, 2011. 